\title{
An Effective Optimization Technique of Extracted Watermark Image Using Particle Swarm Optimisation
}

\author{
${ }^{1}$ Mr. M. Selvaganapathy and ${ }^{2}$ Dr. R. Kayalvizhi \\ ${ }^{1}$ Ph.D. Scholar, Annamalai University, Annamalai Nagar, Chidambaram, Tamil Nadu, India \\ ${ }^{2}$ Professor and Head, Annamalai University, Annamalai Nagar, Chidambaram, Tamil Nadu, India \\ ganapathyselva111@gmail.com
}

\begin{abstract}
:
Nowadays the presence of noises in the extracted image is a major constrain in the Image Processing environment. An ultimate goal of this paper is to optimize the watermark image using particle swarm optimization. Earlier, the research focused on the video watermarking process where the watermark image is embedded into the video as invisible and can be sent to the receiver side for an extraction. While at the extraction stage, the image what embedded was not been retrieved at the receiver side due to the presence of various noises and occurance of errors in the medium. Hence while comparing the extracted image with the original image, the accuracy was poor and non reconstructable. So this paper serves solution for the above said problem using Particle Swarm Optimization Technique. As the end, the extracted image can be reconstructed to the maximum extent as equal to the input image. This scheme can be widely used in the Medical Imaging application, Defence, etc.
\end{abstract}

Keywords

Video Watermarking, Particle Swarm, Embedding, Extraction, Image reconstruction, Optimization.

\section{A. INTRODUCTION}

Particle Swarm Optimization (PSO) is a sturdy technique based on the drive and intelligence of swarms. This Optimization technique applies the concept of social interaction to problem solving techniques. This Optimization Technique was developed by James Kennedy and Russell Eberhart in the year 1995 .

PSO is considered to be an efficient optimization algorithm by searhcing an entire high dimensional problem space. It uses number of agents considered as particles; that constitute a swarm moving around in the search space looking for the best solution. Each particle is considered as a point in an $\mathrm{N}$ - dimensional space which adjusts as a flying experince of other particles. In particle swarm optimization, if a member finds a desirable path, the rest will be followed by the swarms. Each member learns not only from its own experience but from others especially from the best performer. As of the Particle Swarm Optimization, there are two variants which are Basic Variant Particle Swarm Optimization and Modification variant Particle Swarm Optimization. The basics of Particle Swarm Optimization include:

The standard version of the PSO algorithm is essentially described by the following two simple velocity and position update equations, shown in 1 and 2 respectively.

$$
\mathrm{V}_{\mathrm{id}}(\mathrm{t}+1)=\mathrm{W} \mathrm{V}_{\mathrm{id}}(\mathrm{t})+\mathrm{C}_{1} \mathrm{R}_{1}\left(\mathrm{P}_{\mathrm{id}}(\mathrm{t})-\mathrm{X}_{\mathrm{id}}(\mathrm{t})\right)+
$$
$\mathrm{C}_{2} \mathrm{R}_{2}\left(\mathrm{G}_{\text {bid }}(\mathrm{t})-\mathrm{X}_{\text {id }}(\mathrm{t})\right)$--- (1)

and

$$
X_{i d}(t+1)=X_{i d}(t)+V_{i d}(t+1)---(2)
$$

Where,

$$
\mathrm{W}=\mathrm{W}_{\max }-\left(\mathrm{W}_{\max }-\mathrm{W}_{\min }\right) / \mathrm{T} \times \mathrm{t}
$$


$\mathrm{W} \rightarrow$ Inertia weight.

$\mathrm{W}_{\max } \rightarrow$ Intial Weight.

$\mathrm{W}_{\min } \rightarrow$ Final Weight.

$\mathrm{T} \rightarrow$ Maximum Iteration.

$\mathrm{t} \rightarrow$ Current Iteration.

$\mathrm{V}_{\text {id }} \rightarrow$ Rate of position change (velocity).
$\mathrm{X}_{\mathrm{id}} \rightarrow$ Position of the $\mathrm{i}^{\text {th }}$ particle in the $\mathrm{d}^{\text {th }}$ dimension.

$\mathrm{P}_{\mathrm{id}} \rightarrow$ Historically best position of the $\mathrm{i}^{\text {th }}$ particle in the $\mathrm{d}^{\text {th }}$ dimension.

$\mathrm{R}_{1}$ and $\mathrm{R}_{2} \rightarrow \mathrm{n}$ - dimensional vectors.

$\mathrm{c}_{1}$ and $\mathrm{c}_{2} \rightarrow$ Cognitive and Social parameters.

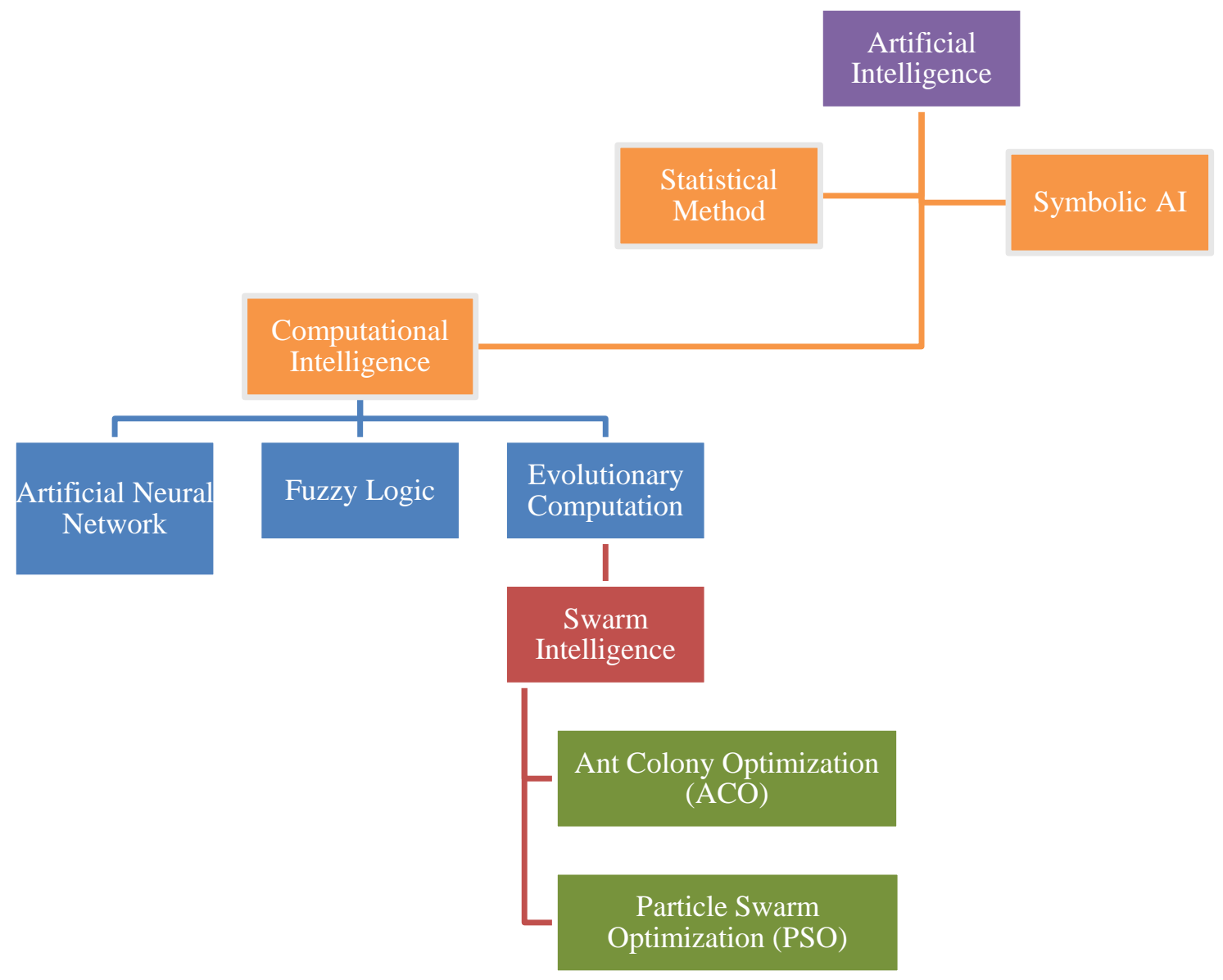

Fig. 1 - Background of Particle Swarm Optimization

\section{B. WORK FLOW OF THE PROJECT}

Step 1: Initialize the particles.

Step 2: Calculate the fitness value for each particles.

Step 3: If fitness value is better than the particles best fitness value $\left(\mathrm{P}_{\text {best }}\right)$ in the history set current value as the new $\mathrm{P}_{\text {best }}$.

Step 4: Repeat step 2 and 3 for all the particles.

Step 5: Choose the particle with best fitness value compared to all the particles and label as the global best $\left(\mathrm{g}_{\text {best }}\right)$.

Step 6: Calculate and update each particles velocity and position for all the particles.

Step 7: Calculate the fitness value for each particles.
Step 8: If a minimum error criterion ((i.e.) desired fitness value of $90 \%$ of all the particles) is not achieved, goto step 3 .

Step 9: Display the particles.

The following diagram represents the research flow graph where the particle swarm optimization undergoes various level of updation inorder to get the optimized swarm output. Initially, the process initializes the supersparm where the image consists of multiswarm in which the Supersprams are identified. Those superswarms are considered to be the super sized swarm. Then the process is continued to evaluate the fitness of each particles of the swarms. This inturn measures the dimension of the particle or swarm 
parameters. The next process is to initialize all the subswarms following to the superswarms and then the object functions are evaluated inorder to get the fitness value of each particle or swarm. Once the process is completed, the updation of particles were made and continued to the further movement. Similarly, the same process is repeated for the swarm parameters too as a separate condition. Hence this process serves as the main work flow in enhancing the quality of the swarms using Particle Swarm Optimization.

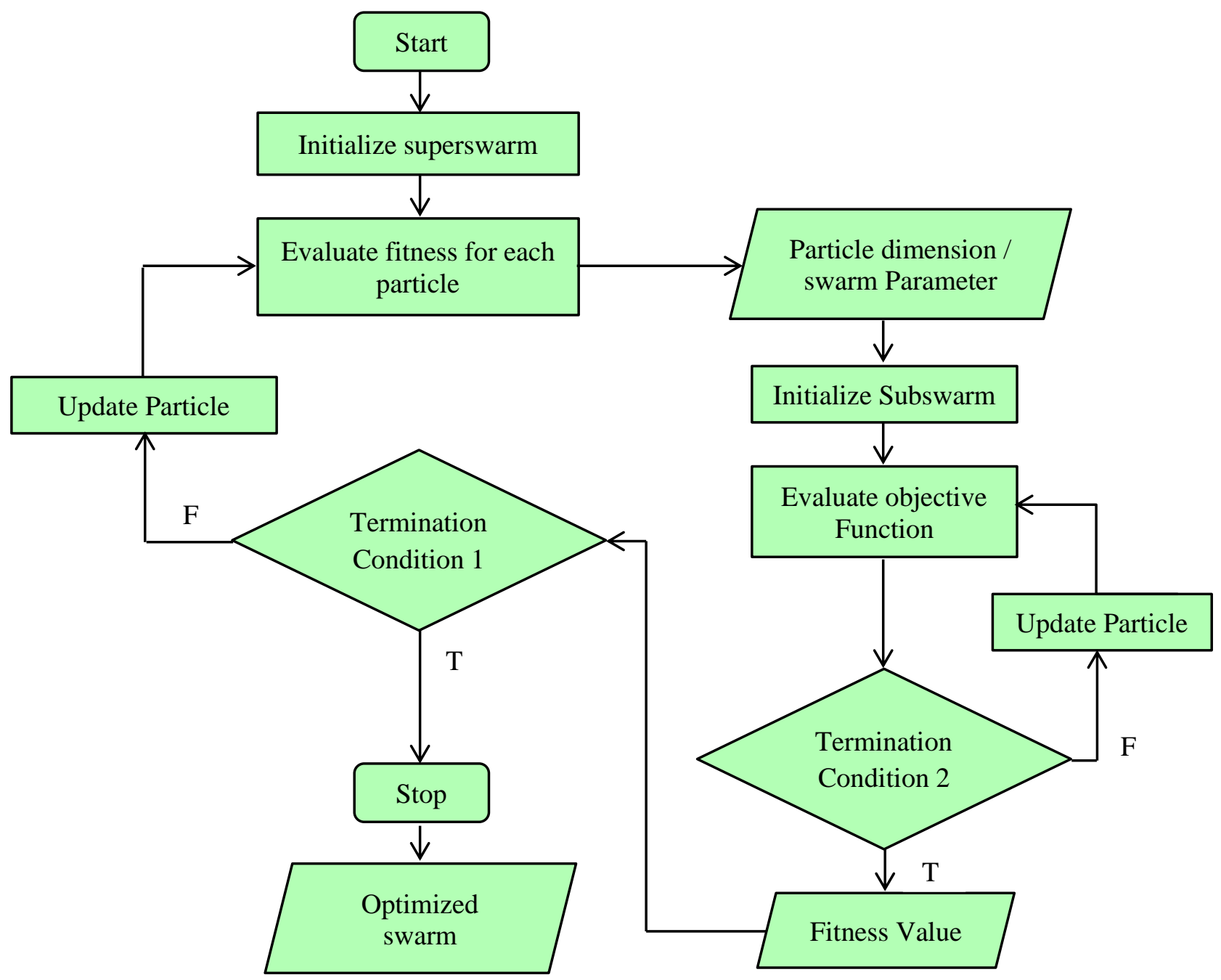

Fig. 2 - Basic Work Flow Graph of Proposed optimization technique

\section{OBJECTIVE OF THE RESEARCH}

\section{General Objective}

The general objective of the research is to enhance the quality of an image using Particle Swarm Optimization.

\section{Specific Objective}

The specific objective of the research includes:

1. To improve the interpretability of an image.

2. To improve image perception.

3. To reduce the noise occurrence.
4. To improve the better output.

\section{BLOCK DIAGRAM}

In this method, the local gain parameters were used. Along with the above said parameters, the problems with other image enhancement techniques were overcome. The following diagram is the block diagram for the proposed research where the extracted image can be enhanced using Contrast Limited Adaptive Histogram Enhancement (CLAHE) method. 


\section{CLAHE}

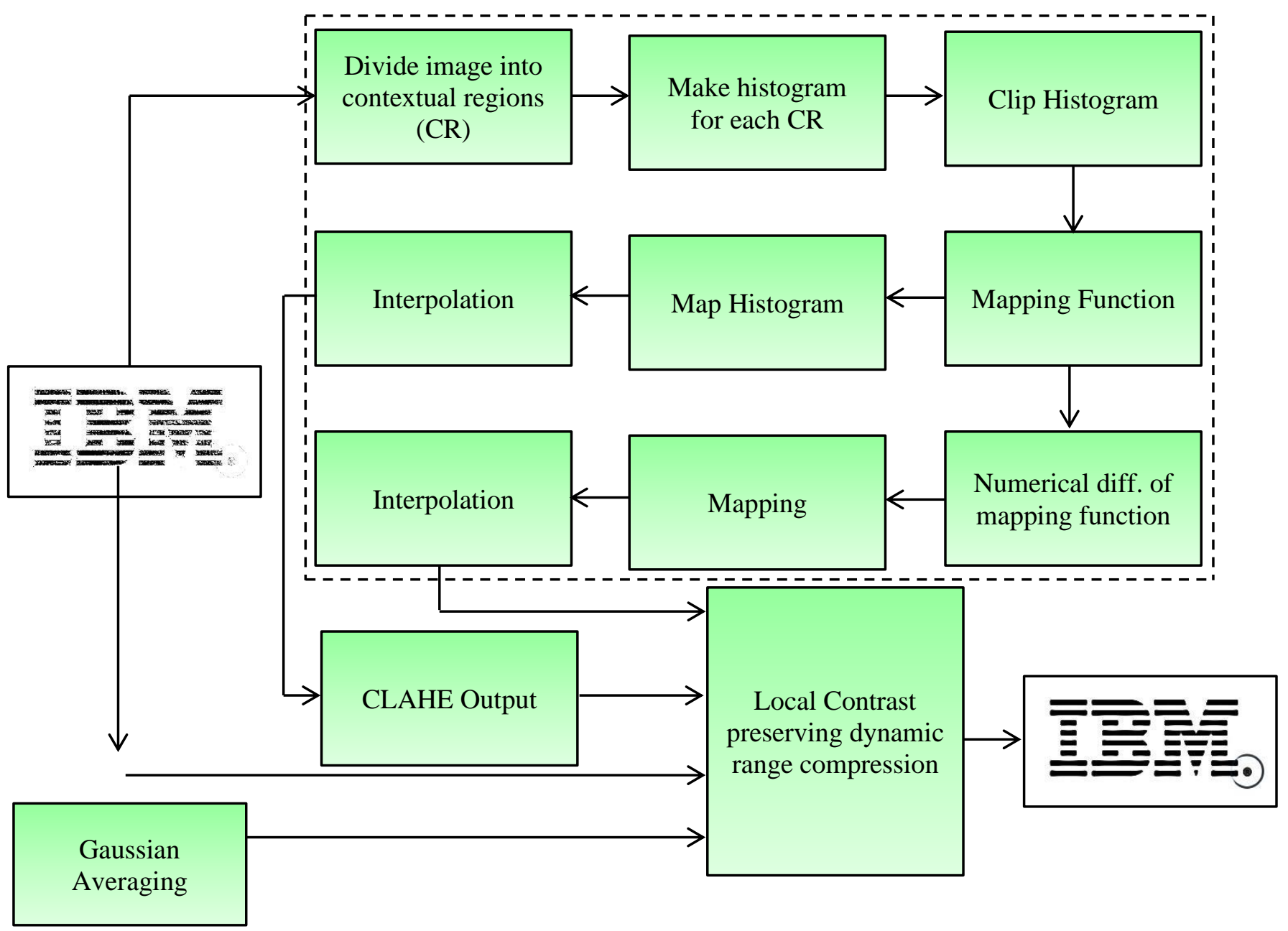

Fig. 3 - Overall Block Diagram of the Proposed System

\section{E. SIMULATION RESULT}

The proposed algorithm has been tested with various numbers of Logos, medical images and images downloaded from the internet databases. Based on the various images, the following result has been obtained. In this section, the various performance of the image enhancement method is discussed over. The parameters taken into the considerations are Peak Signal to Noise Ratio (PSNR) and Bit Correction Rate (BCR). And the Simulation Result for the proposed algorithm stands the following table which is prescribed in the Table 1.

\begin{tabular}{|l|c|c|c|c|c|}
\hline \multicolumn{1}{|c|}{ Attacks } & Parameters & \multicolumn{2}{c|}{ PSNR } & \multicolumn{2}{c|}{ BCR } \\
\hline Without Attack & W/O PSO & With PSO & W/O PSO & With PSO \\
\hline JPEG Compression & QF $=20$ & 43.6064 & 63.6599 & 0.9914 & 0.9917 \\
\hline Gaussian Noise & Noise $=3 \%$ & 42.7871 & 63.8049 & 0.9937 & 0.9939 \\
\hline Uniform Noise & Noise $=5 \%$ & 42.0378 & 54.1498 & 0.9902 & 0.9905 \\
\hline
\end{tabular}




\begin{tabular}{|l|c|c|c|c|c|}
\hline Salt \& Pepper & Noise = 10\% & 36.1234 & 40.1291 & 0.7513 & 0.7732 \\
\hline Low Pass Filter & STD Devi = 10 & 40.3923 & 49.5222 & 0.9688 & 0.9697 \\
\hline Median Filter & $=5$ & 43.3176 & 61.7385 & 0.9817 & 0.9854 \\
\hline Sharpening & --- & 40.9541 & 50.1475 & 0.9914 & 0.9943 \\
\hline Gamma Correction & Value = 5 & 32.2006 & 34.0687 & 0.9997 & 0.9999 \\
\hline
\end{tabular}

\section{Table 1 - Simulation Result of the proposed algorithm}

From the above table it is clear that with PSO, the PSNR value is improved to 63.6599 from 43.6064. As like, it is found to be an improved PSNR for all the cases when the images are submerged into various attacks and noises. Also, it is found that the Bit Correction Rate for all the images with PSO seems to be quiet impressive and improved.

\section{F. REFERENCES}

1. U. Khusanov and C. H. Lee, "Image Enhancement based on local histogram specification", Journal of Korean Institute of Intelligent System, Vol. 23, No. 1, pp. 18 - 23, 2013.

2. D. Ghimire and J. Lee, "Non linear transfer function based image detail preserving dynamic range compression for color image enhancement", Advance Image and Video Technology, pp. 1 - 12, 2012.

3. C. C. Sun, S. J. Ruan, M. C. Shie and T. W. Pai, "Dynamic contrast enhancement based on histogram specifications", IEEE Transactions on Consumer Electronics, Vol. 51, No. 4, pp. $1300-1305,2005$.

4. N. J. Kim and Y. S. Kim, "Image contrast enhancement Technique using clustering algorithm", Jounal of Korean Institute of Intelligent Systems, Vol. 14, No. 3, pp. 310 315, 2004.

5. G. B. Lee, Y. S. Kim, "An image contrast enhancement technique using improved integraed adaptive fuzzy clustering model", Journal of Korean Institute of Intelligent Science, Vol. 11, No. 9, pp. 777 - 781, 2003.
6. D. J. Jobson, Z. U. Rahman and G.A Woodbell, "Statistics of visual perception", Proceedings of SPIE, Vol. 4736, 2002.

7. G. Ramponi, N. K. Strobel, S. K. Mitra and T. $\mathrm{H}$. Yu, "Non - linear unsharp masking methods for image contrast enhancement", Journal of Electronics Imaging, Vol. 5, No. 3, pp. 353 - 366, 1996.

\section{AUTHOR(S) BIOGRAPHY}

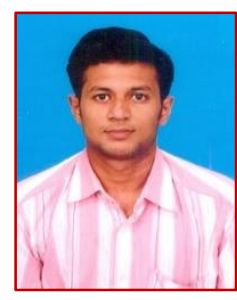

Mr. M. Selvaganapathy is currently working as an Assistant Professor in CK College of Engineering and Technology, Cuddalore. He is pursuing his Ph.D., in Annamalai University. He completed his Under Graduate and Post Graduate in Anna University. His research areas are Digital Image Processing, Wireless Networks and Embedded Automations. He has published fifteen research papers both nationally and internationally. $\mathrm{He}$ is a life time member in Indian Society for Technical Education, Indian Association for Engineers and an annual member in Institute of Electrical and Electronics Engineers

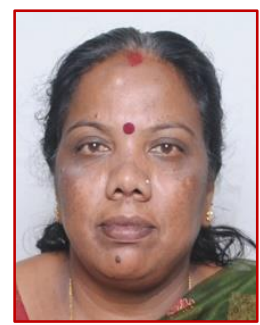

Dr. R. KAYALVIZHI has obtained B.E (Electronics and Instrumentation), M.E (Power Systems) and $\mathrm{PhD}$ in Instrumentation Engineering from Annamalai University in 1984, 1988 and 2007 respectively. She is currently working as a Professor in the Department of Electronics and Instrumentation Engineering at Annamalai University where she has put in 32 years of service. She produced $5 \mathrm{PhDs}$ and presently guiding $5 \mathrm{PhD}$ scholars. Her research papers 25 have been presented in the International and National conferences. She has 35 publications in National Journals and 30 in International Journals. Her areas of research interest include Power Electronics, Power Systems and Digital Image Processing. She is a life member of Indian society for Technical Education. 